\title{
Do Work Values Predict Preference for Organizational Values?
}

\author{
Juliana Moraes de Sousa - Universidade de Brasilia, Brasília, Brasil \\ Juliana Barreiros Porto - Universidade de Brasilia, Brasilia, Brasil
}

\begin{abstract}
The purpose of this research is to identify evidence that work values can predict organizational values preference, based on conceptual similarity proposed by the Theory of Values. A total of 254 Brazilian undergraduate students responded to the Organizational Values Scale and the revised Work Values Scale. Hierarchical regressions were run controlling for demographics. The results indicated significant explanation of variance for all organizational values. The most significant predictors were compatible with the hypotheses based on Schwartz's Theory of Values, revealing that work and organizational values are logically connected through an axiological structure. In conclusion, work values and preferred organizational values have adequate nominal commensurability for conducting Individual-Organization fit studies and implications for organizational socialization and vocational and career counseling.

Keywords: values, organizational behavior, organizational psychology, individual-organization fit, theory of values
\end{abstract}

Valores do Trabalho Predizem Preferências por Valores Organizacionais?

\begin{abstract}
Resumo
O objetivo desta pesquisa é identificar a predição de valores do trabalho sobre a preferência por valores organizacionais, de maneira coerente, com a similaridade conceitual prevista pela Teoria de Valores. Responderam à Escala de Valores Organizacionais e a Escala de Valores do Trabalho revisada 254 estudantes de graduação. Regressões hierárquicas foram realizadas controlando os dados demográficos. Os modelos apresentaram explicação significativa para todos os valores organizacionais. Todos os preditores mais importantes mostraram-se compatíveis com hipóteses baseadas na teoria, revelando que valores do trabalho e valores organizacionais são logicamente conectados por meio de uma estrutura axiológica. Conclui-se que esses construtos possuem comensurabilidade nominal adequada para a condução de estudos de compatibilidade (IO), assim como aplicações no campo da socialização organizacional, orientação profissional e de carreira.

Palavras-chave: valores, comportamento organizacional, psicologia organizacional, compatibilidade indivíduo-organização, teoria dos valores
\end{abstract}

\section{Valores del Trabajo Predicen Preferencias por Valores de Organización?}

\begin{abstract}
Resumen
El objetivo de esta investigación fue identificar los valores predictivos del trabajo en la preferencia por los valores de la organización, de manera coherente con la similitud conceptual prevista por la Teoría de Valores. Respondieron 254 estudiantes universitarios la Escala de Valores de la Organización y la Escala de Valores del Trabajo. Regresiones jerárquicas fueron realizadas controlando los datos demográficos. Los modelos presentaron explicación significativa para todos los valores de organización. Todos los predictores más importantes fueron compatibles con hipótesis basados en la teoría, revelando que valores de trabajo y valores de organización están conectados lógicamente a través de una estructura axiológica. Se llegó a la conclusión de que esos constructos tienen conmensurabilidad nominal adecuada para llevar a cabo estudios de compatibilidad (IO), así como aplicaciones en el campo de la socialización organizacional, orientación profesional y de carrera.

Palabras clave: valores, comportamiento organizacional, psicología de las organizaciones, compatibilidad individuo-

organización, teoría de valores
\end{abstract}

\section{Do Work Values Predict Preferences for Organizations?}

Values are people's abstract ideals, play a central role in individual belief systems, and influence their actions and choices (Rokeach, 1981). Thus, identifying how work organizations are related to people's values can enable the construction of healthier working relationships and increase people's well-being. One way to study this topic is through the fit between the values of the individual and the organization.

Person-Organization (PO) fit is the compatibility between individual and organizational characteristics that can occur when one of these parts (individual or organization) meets needs of the other-complementary fit, and/or even when they share similar fundamental characteristics, such as values, goals, or personality - supplementary fit (Kristof-Brown, Zimmerman, \& Johnson, 2005; Verquer, Beehr, \& Wagner, 2003). The compatibility between the individual values and organizational values dimensions has been under study since the 1990s (e.g., O’Reilly, Chatman, \& Caldwell, 1991), though there is a lack of studies that test the theoretical fit between these axiological structures, i.e., that identify conceptual similarity underlying the motivational types. The identification of this similarity is essential 
for determining which individual values are associated with the core of the organizational culture in order to predict greater compatibility between the person and the organization.

Additionally, the lack of evidence about the theoretical fit represents a significant gap. In order to use more advanced techniques in the fit area that permit a more in-depth analysis of the effects of PO fit on organizational and individual results, it is necessary to identify commensurate dimensions of the individual and organizational variables (Kristof-Brown et al., 2005), with nominal and scalar equivalences (Edwards, 2002).

Specifically in the case of values, it is worth noting that depending on the level (cultural, organizational, or individual) at which the variables are treated, different structures can emerge. In this sense, Schwartz (1992; 1994b) found that individual-level values present a structure different from cultural-level values. Despite these different structures, similarities between the individual and organizational level are expected from the second order dimensions - two thematic axes that summarize the relations of compatibility and conflict between the values - which would govern values from different levels (Borg, Groenen, Jehn, Bilsky, \& Schwartz, 2011; Porto \& Pilati, 2010; Sagiv \& Schwartz, 2007). Therefore the second order dimensions would allow identification of conceptual similarity (nominal commensurability) between individual and organizational attributes, despite the different structures of their respective constructs.

In the context of organizational psychology, most studies use preferred organizational values to gauge the individual dimension of PO fit (Kristof-Brown et al., 2005), as there are few studies using individual values related to work. One of the factors contributing to this is the absence of evidence that work values present alignment with the dimensions of organizational values. This study intends to fill this gap by testing the relationship between the structures of work values and organizational values based on individual preferences for an ideal organization.

From the congruence principle whereby we value a belief system in proportion to its degree of fit with our own belief system (Rokeach, 1981), it is to be expected that people seek out organizations that prioritize values similar to their own. Thus, using the preference for organizational values makes it possible to test whether second order dimensions guide both organizational values and work values. Based on evidence that individuals tend to choose work situations with axiological content similar to their own values (Judge \& Bretz, 1992), it is possible to test whether work values predict the preference for organizational values. In this case, by identifying an integrated structure between work and preferred organizational values, one can evaluate the existence of commensurability between work and organizational values, establishing the foundations for a refinement of the explanatory theories of the processes at work in the formation of the values fit between the person and the organization.

Thus, the objective of this research is to identify whether work values predict the preference for organizational values consistent with the conceptual similarity predicted by Schwartz's theory (1994b). The evidence that the theoretical model applies to the study of values at the two levels of analysis enables the development of studies on individual-organization compatibility, as well as applications in the field of organizational socialization and vocational and career guidance. It is hoped that these results can guide fit studies using values constructs based on Values Theory. By identifying conceptual similarity between preferred organizational values and work values, support is found for using both constructs in fit studies, rather than merely a preference for organizational values, which is the construct generally employed in the area (Kristof-Brown et al., 2005). Further details on the Theory of Values underlying this study will be presented below.

\section{Values}

The concept of values anchoring this study was developed from the Theory of Values (Schwartz, 1992). Schwartz (1992) proposed that values are "concepts or beliefs, about desirable states or behaviors, transcend specific situations, guide selection or evaluation of behavior and events, and are ordered by relative importance" (Schwartz, 1992, p. 4). Based on this concept, values can be contextualized, and in this study work values are defined as principles that guide the individual's life at work. Preferred organizational values, in turn, are understood as the individual's preference for principles that guide the life of the organizations.

The Schwartz theory of values proposes a circular structure composed of a continuum of motivations that form dynamic relations of compatibility and conflict among values. Making use of ample empirical testing, Schwartz (1992) proposed a personal values structure consisting of ten motivational types that can 
be summarized in two second order dimensions, as follows (Schwartz, 1994a):

1) Openness to Change versus Conservation, which considers the opposition between values that emphasize independent thinking and action favoring change, in relation to those that emphasize self-restraint, submission, preservation of traditional practices, as well as protection and stability; and

2) Self-Enhancement versus Self-Transcendence, a dimension placing in opposition values that emphasize acceptance of others as equals and concern for the welfare of others, versus values that emphasize achievement by the individual and dominance over others.

Subsequently, the author obtained evidence of validity that the model could be transposed to the cultural level. The change in level of analysis influenced the structure of cultural values, since values were now based on the needs of societies and no longer of individuals. The values were grouped into seven dimensions (Schwartz, 1994b), forming a values continuum that considered opposing relationships with one another, namely:

a) Egalitarianism (transcendence of egotistical interests in favor of voluntary commitment to promoting the well-being of others) versus Hierarchy (cultural preponderance of legitimating the unequal distribution of power, roles, and resources);

b) Harmony (harmonious adjustment to the environment) versus Dominance (being ahead of others by means of self-assertion); and

c) Affective and Intellectual Autonomy (desire of individuals to have positive affective experiences, to have their own ideas and intellectual direction) versus Conservatism (maintaining the status quo and restraint of actions or inclinations that might corrupt the traditions and solidary order of the group).

It is noteworthy that there is evidence that the same basic and broad principles, represented by the second order dimensions found primarily at the individual level, govern both cultural and personal values (Schwartz, 1994b). Accordingly, the cultural dimension of Affective and Intellectual Autonomy versus
Conservatism can be associated with the second order axis, Openness to Change versus Conservation, while the Hierarchy versus Egalitarianism dimension and the Mastery versus Harmony dimension have a parallel in relation to the second order axis, Self-Enhancement versus Self-Transcendence at the individual level.

Studies have shown that work values have a specific structure, which is at the same time compatible with the Theory of Values (Porto \& Pilati, 2010; Ros, Schwartz, \& Surkiss, 1999). In the study by Porto and Pilati (2010), the work motivational types (WV) were associated with the second order dimensions. The work values were designated as: Universalism and Benevolence WV (seeking positive social relations and positive contribution to society through work), which can be linked to the Self-Transcendence dimension; Achievement WV (personal success through demonstrated competence according to social standards), and Power WV (seeking authority, professional success, and power of influence at work), which can be associated with the Self-Enhancement dimension; Self-Direction and Stimulation WV (independent thinking and action, seeking excitement, novelty, and challenge in life), which can be associated with the second order dimension, Openness to Change; and Security WV (stability and order in life to materially meet personal needs), and Conformity WV (restriction of actions, inclinations, or impulses that tend to upset or harm others and that violate social expectations or norms; respect, commitment, and acceptance of ideas that the individual's culture or religion provide), which can complete the Conservation dimension.

Preferred organizational values are the organizational values assessed by individuals as desirable in an ideal organization. They have also presented a framework that allows a theoretical fit with the Theory of Values (Sousa \& Porto, 2012). The motivational types found for preferred organizational values (POV) are presented below, along with the second order dimension with which they can be associated: Mastery POV (control over people, resources, and other organizations without concern for the environmental and social consequences of one's actions), which comprises the Self-Enhancement dimension and is opposed to the Harmony POV (peaceful coexistence with society and the environment) and the Egalitarianism POV (transcendence of individual interests towards equal treatment of all employees, promoting the health and well-being of workers and teams), both of which can be linked to the Self-Transcendence dimension; 
Conservatism and Hierarchy POV (preserving unequal distribution of power between hierarchical levels and maintaining the traditional form of organizational operation), that comprises the Conservation dimension and opposes the Innovation POV (use of creativity in its products, services, and management practices and outstanding market reach by openness to new ways of working) associated with Openness to Change.

From the theoretical framework of Values Theory, we expect a stronger positive relationship between the WV motivational types and the POV motivational types that are aligned with a single second order dimension, just as a stronger negative relationship is expected between the motivational types belonging to conflicting second order dimensions. Thus, the following hypotheses were developed, summarized in Figure 1:

Hypothesis 1: Harmony POV and Egalitarianism POV motivational types have a stronger positive relationship with the WV motivational type(s) that comprise Self-Transcendence, and likewise have a stronger negative relationship with the WV motivational type(s) that comprise Self-Enhancement.

Hypothesis 2: Mastery POV motivational type presents a more intense positive relationship with the WV motivational type(s) that comprise Self-Enhancement, as well as a stronger negative relationship with the WV motivational type(s) that comprise Self-Transcendence.

Hypothesis 3: Conservatism and Hierarchy POV motivational type has a stronger positive relationship with the WV motivational type(s) that comprise Conservation, as well as a stronger negative relationship with the WV motivational type(s) that comprise Openness to Change.

Hypothesis 4: Innovation POV motivational type has a stronger positive relationship with the WV motivational type(s) that comprise Openness to Change, as well as a stronger negative relationship with the WV motivational type(s) that comprise Conservation.

The above assumptions deal with relationships between variables and not with predictions. Before proceeding with the predictive hypothesis, it is fitting to point out that demographics may affect the preference for certain organizational attributes (Schneider, Goldstein, \& Smith, 1995). Therefore, the testing of the predictive power of work values should consider the impact of these variables on preferred organizational values. Therefore, the following hypothesis was developed:

Hypothesis 5: Controlling for the demographic variables, the WV motivational types belonging to the same POV second order dimension are the strongest POV positive predictors, or even, the WV motivational types belonging to the second order dimension opposed to that of the respective POV, are the most intense negative predictors of the respective preference for organizational values.

\section{Method}

\section{Participants}

The sample consisted of 254 students from two higher education institutions in Brazil's Federal District (DF), with $65 \%$ of participants tied to a public institution and the majority of the sample being women $(61 \%)$, without work at the present time (53\%), with ages between 17 and 56 years $(M=22.87 ; S D=6.16)$, and belonging to the Catholic religion (37\%). As it was intended to evaluate the organizational values of an idealized organization, and not the values of a specific organization, the student sample was chosen.

\section{Instruments}

The Preferred Organizational Values Scale (POVS) was developed from an instrument to measure the perception of organizational values (Porto, Ferreira, \& Fonseca, 2014). The 79-item scale was submitted to participants, who were to think of an organization where they would like to work, and then answer how much they would like this ideal organization to prioritize the organizational values listed. The response scale contained 11 points $(0=$ not important at all and $10=$ extremely important). The final solution of the multidimensional scaling (MDS) for this sample retained 31 values, grouped into five motivational types (S-Stress $=.14$; Tucker's congruence coefficient $=.97):$ 1) Harmony $(n=4, \alpha=.71) ; 2)$ Egalitarianism $(n=5, \alpha=.73)$; 3) Innovation ( $\mathrm{n}=6, \alpha=.72)$; 4) Mastery $(n=5, \alpha=.62) ; 5)$ Conservatism and Hierarchy $(n=11, \alpha=.86)$.

The Work Values Scale - Revised - WVS-R (Porto $\&$ Pilati, 2010) consists of 36 items that represent work values requiring an evaluation of their level of importance on a five-point scale (1 - not important at all; 2 - of little importance; 3 - important; 4 - very important; 5 - extremely important). The MDS conducted on the sample from this survey indicated the presence of four motivational types (S-Stress $=.17$; Tucker's congruence coefficient $=.96)$ : 1) Self-Direction and Stimulation ( $n=11, \alpha=.86), 2)$ Universalism and Benevolence ( $n=7, \alpha=.84), 3$ ) Conformity $(n=5, \alpha$ 


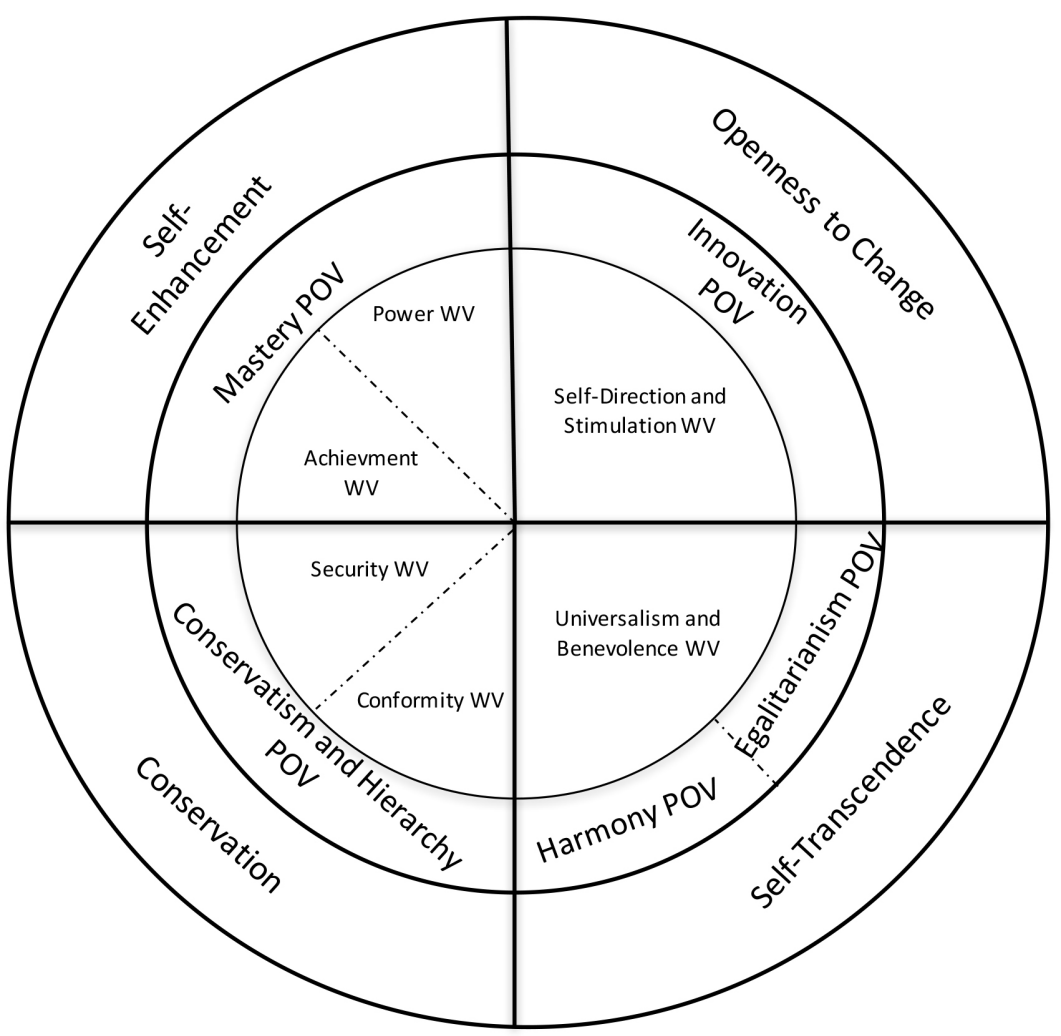

Figure 1. Hypotheses. Representation of the hypotheses for relationship and prediction between the WV (Work Values, inner circle) and POV (Preferred Organizational Values, middle circle) motivational types, as well as the association of the variables with the second order dimensions of the Theory of Values (outer circle).

$=.77), 4)$ Power, Achievement, and Security $(n=13, \alpha$ $=.88)$. The aforementioned structure is similar to that found in previous studies, such as the one by Porto and Pilati (2010), except for the unification of the motivational types, Power, Achievement, and Security, which formerly appeared separately. In spite of the difference found, the analysis of the MDS structure maintained theoretical alignment with the Schwartz second order dimensions (1992).

Demographic variables included in the questionnaire were: sex, type of college (public or private), age, current work situation (whether the person is currently working or not), religion, number of children, marital status, and education.

\section{Data Collection Procedures}

The questionnaires were administered to university students in classrooms, with the teacher's consent. The team member responsible for their application provided the basic guidelines and information about the research to be conducted. Participation was voluntary and offered no financial benefits or awards to participants. It is emphasized that the research project was approved by the Ethics Committee on Human Research at the School of Health Sciences, University of Brasilia, with IRB no. 186/11.

\section{Data Analysis Procedures}

Extreme cases above 3.26 standard deviations for each motivational type were removed from the analyses, leaving 240 valid cases. Due to the use of the list wise method, 11 cases were excluded for having a missing value in the controlled variables, leaving 229 cases used in the regressions. The coding of the demographic variables was: a) sex: female $=0$, male $=1$; b) college: private college $=0$, public college $=1 ; \mathrm{c}$ ) current employment status: working $=0$, not working $=1$.

The WV and POV motivational types were centralized by the mean of the individual responses to the questionnaire items, as suggested by Schwartz (1992). After the exploratory analyses and initial examination of the data, one-tailed Pearson correlations, using 
the listwise method, were run, between the POVs and the WVs.

Five hierarchical multiple regressions were performed, containing demographic data as controlled variables in the first model. It was observed, by analyzing residuals histograms and the P-P graphics, that all the regressions showed normality, homoscedasticity, and multivariate linearity. Initially, the multicollinearity indicators (VIF and tolerance) violated the collinearity parameters, which is why only the motivational types with theoretical and empirical sense were allowed in the regression models, according to the procedure described by Schwartz (2003). After using this criterion, the multicollinearity indicators (VIF and tolerance) were within expectations. In the second hierarchical regression model, the three $\mathrm{WV}$ motivational types with higher correlation with each of the POVs were included as predictors.

\section{Results}

With respect to the correlations, the magnitudes of the most significant coefficients found were of moderate strength, as shown in Table 1 . All the results found in terms of a more significant positive relationship appear as expected. As for the inverse relationships, one single discrepancy was observed in relation to the expected regarding the negative relationship between Conformity WV and Egalitarianism POV stronger than between this POV and the Power, Achievement, and
Security WV. Thus, considering the strongest negative and positive relationships between the $\mathrm{WV}$ and POV motivational types, the predicted relations were identified, fully corroborating hypotheses 2 through 4, and partially, hypothesis 1.

The statistical results from the regressions are summarized in Table 2, and in Figure 2 the significant regression results are represented in a circular structure of values. The regression models explained between 19 and $32 \%$. For the organizational values of Conservatism and Hierarchy, Harmony and Egalitarianism, the work values that show compatible motivation were the variables that more strongly explained these organizational values. For the organizational values of Mastery and Innovation, the work values with opposite motivation were those that contributed more strongly, indicating support for hypothesis 5 .

\section{Discussion}

It can be concluded that the analyses of the results showed consistent evidence that work values are predictors of the preference of individuals for organizational values. Furthermore, the hypotheses conjectured from the Theory of Values (Schwartz, 1992) were in large part corroborated, suggesting that this theory contributes to the proposition of an effective integrated system of work values and preferred organizational values. For most cases, after the inclusion of work values with a stronger relationship with organizational

Table 1

Summary of One-Tailed Correlations between Work Values and Preferred Organizational Values

\begin{tabular}{lcccccc}
\hline \multicolumn{7}{c}{ Work Values } \\
\hline $\begin{array}{l}\text { Preferred organizational } \\
\text { values }\end{array}$ & SD/ST & CONF & PO/AC/SE & UN/BE & Mean & $\begin{array}{c}\text { Standard } \\
\text { Deviation }\end{array}$ \\
\hline Conservatism and hierarchy & $-0.29^{* * *}$ & $0.42^{* * *}$ & 0.08 & $-0.18^{* *}$ & -0.67 & 0.81 \\
Mastery & -0.05 & 0.08 & $0.21^{* * *}$ & $-0.41^{* * *}$ & -0.17 & 1.35 \\
Harmony & -0.04 & -0.07 & $-0.14^{*}$ & $0.36^{* * *}$ & 1.12 & 1.07 \\
Egalitarianism & $0.21^{* *}$ & $-0.32^{* * *}$ & $-0.19^{* *}$ & $0.36^{* * *}$ & 1.03 & 0.95 \\
Innovation & $0.37^{* * *}$ & $-0.46^{* * *}$ & -0.11 & $-0.20^{* *}$ & 1.15 & 0.83 \\
Mean & 0.08 & -0.40 & 0.23 & 0.21 & & \\
Standard deviation & 0.57 & 0.57 & 0.34 & 0.48 & & \\
\hline
\end{tabular}

Note. SD/ST: Self-Direction and Stimulation; CONF: Conformity; PO/AC/SE: Power, Achievement, and Security; UN/BE: Universalism and Benevolence.

${ }^{*} p<0.05 .{ }^{* *} p<0.01 .{ }^{* * *} p<0.001$. 
Table 2

Results of Hierarchical Multiple Regressions to Predict the Motivational Types of Preferred Organizational Values

\begin{tabular}{|c|c|c|c|c|c|}
\hline \multirow[t]{3}{*}{ Predictor Variables } & \multicolumn{5}{|c|}{ Preferred Organizational Values } \\
\hline & $\mathrm{CO} / \mathrm{HI}$ & MA & HA & EG & IN \\
\hline & $\beta$ & $\beta$ & $\beta$ & $\beta$ & $\beta$ \\
\hline \multicolumn{6}{|l|}{ Model 1} \\
\hline$\Delta \mathrm{R}^{2}$ & $0.11^{c}$ & $0.08^{c}$ & $0.065^{b}$ & $0.08^{c}$ & $0.16^{c}$ \\
\hline Sex & -0.02 & $0.22^{\mathrm{b}}$ & $-0.25^{c}$ & -0.07 & -0.02 \\
\hline College & $-0.36^{c}$ & $0.27^{\mathrm{c}}$ & $0.19^{\mathrm{a}}$ & $0.33^{c}$ & $0.43^{\mathrm{c}}$ \\
\hline Employment status & 0.10 & 0.12 & -0.08 & $-0.19^{\mathrm{b}}$ & -0.06 \\
\hline \multicolumn{6}{|l|}{ Model 2} \\
\hline$\Delta \mathrm{R}^{2}$ & $0.15^{c}$ & $0.16^{c}$ & $0.13^{c}$ & $0.17^{c}$ & $0.16^{c}$ \\
\hline \multicolumn{6}{|l|}{ Work Values } \\
\hline $\mathrm{SD} / \mathrm{ST}$ & 0.11 & $-0.17^{a}$ & & & 0.12 \\
\hline $\mathrm{PO} / \mathrm{AC} / \mathrm{SE}$ & & -0.07 & 0.02 & -0.06 & -0.12 \\
\hline $\mathrm{UN} / \mathrm{BE}$ & $-0.13^{a}$ & $-0.44^{\mathrm{c}}$ & $0.36^{\mathrm{c}}$ & $0.27^{\mathrm{c}}$ & \\
\hline CONF & $0.31^{\mathrm{c}}$ & & -0.07 & $-0.27^{\mathrm{c}}$ & $-0.32^{c}$ \\
\hline Sex & 0.01 & $0.23^{c}$ & $-0.23^{c}$ & -0.08 & -0.07 \\
\hline College & $-0.24^{c}$ & $-0.18^{a}$ & 0.11 & $0.21^{\mathrm{b}}$ & $0.34^{\mathrm{c}}$ \\
\hline Employment status & 0.12 & $0.15^{\mathrm{a}}$ & -0.09 & $-0.21^{b}$ & -0.09 \\
\hline $\mathrm{R}^{2}$ Total & $0.26^{c}$ & $0.24^{c}$ & $0.19^{c}$ & $0.25^{c}$ & $0.32^{c}$ \\
\hline
\end{tabular}

Note. SD/ST: Self-Direction and Stimulation; CONF: Conformity; PO/AC/SE: Power, Achievement, and Security; UN/BE: Universalism and Benevolence; CO/HI: Conservatism and Hierarchy; MA: Mastery; HA: Harmony; EG: Egalitarianism; IN: Innovation.

${ }^{\mathrm{a}} p<0.05,{ }^{\mathrm{b}} p<0.01,{ }^{\mathrm{c}} p<0.001$.

values, the other types failed to provide a significant contribution, probably because the WVs are correlated with one another, so that the interdependence of the variables reduces the impact of some values on the criterion variable. Schwartz (1994b) argued that the second order dimensions regulate the relationship between the individual-level motivational types and the culturallevel dimensions. According to the author, despite the change of level, some similarity would have to remain between cultural and individual values. The results presented here provide evidence that this same logic applies to the work context.

Although hypothesis 5 has been confirmed for the most significant predictors, other WVs showed significant contributions and these results are discussed below. For Mastery POV, the main predictor with an expected direct relationship - Power, Achievement, and Safety WV - did not present a significant impact. On the other hand, unexpectedly, the Self-Direction and Stimulation
WV proved to be a significant predictor of the negative relationship with the criterion variable Mastery POV. This result may be due to the presence of Security items, which typically have content underlying the Conservation dimension (Schwartz, 1992; Schwartz et al., 2012), within the Power, Achievement, and Security WV, which comprised the Self-Enhancement second order dimension in this study. As shown in Figure 1, it was expected that the Security WV was included in the Conservation dimension, which did not occur with this sample. Thus, it is possible that the Security WVs have weakened the essential content of Self-Enhancement that emphasizes attainment of success by the individual and dominance over others (Schwartz, 1994a).

As regards the Egalitarianism POV, the negative relationship found with the Conformity WV was not hypothesized. Nevertheless, one possible explanation for this result comes from Schwartz (1994b), who found negative correlations, moderate to strong, between 


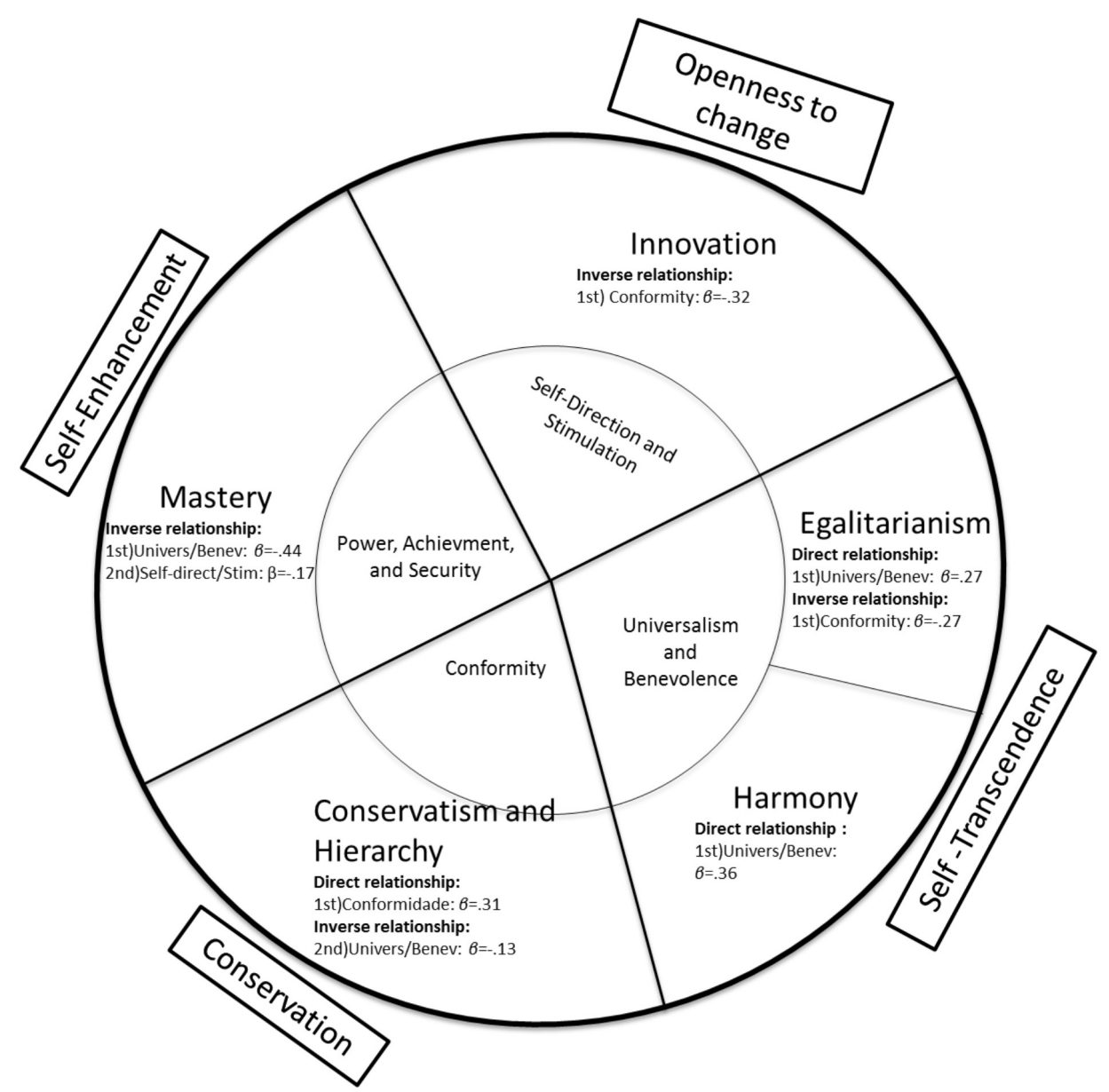

Figure 2. Results. Pictorial representation of the regression results, associating the WVs (inner circle) that proved the most significant predictors of each of the POVs (outer circle), controlling for gender, type of college, and current employment status. In the absence of predictors with a positive and significant relationship with the POV, the association between the WV with the motivational type theoretically opposed to the one found having the most negative relationship with the criterion variable is represented.

Egalitarianism and Hierarchy, at the cultural level. Since the Conformity WV is a significant predictor of Conservatism and Hierarchy POVs, this POV motivational type shows itself partially opposed, in the structure of the preferred organizational values, to Egalitarianism. This result shows consistency with the unexpected significantly negative relationship found between Conservatism and Hierarchy POV and Universalism and Benevolence WV, since the Egalitarianism POV and the Universalism and Benevolence WV are part of the same second order dimension, Self-Transcendence. This dimension is opposed to Conservation, to which the Conservatism and Hierarchy POV and the Conformity WV are linked (Schwartz, 1992, 1994b; Sousa \& Porto, 2012).
Work values proved to be predictors of the preference for organizational values with similar axiological content. Perhaps this result was due to the satisfaction of underlying needs that these values promote. That is, work values are manifestations of the underlying individual needs that can be met through organizational contexts that promote satisfaction of these desires, affecting preference for organizational values.

\section{Final Considerations}

The results of this study support the conclusion that the second order dimensions apply similarly both to preferred organizational values and to work values, despite the differences in construct levels and 
singularities of each construct. As preference for organizational values is a construct empirically closer to actual organizational values and assuming that organizational values have presented evidence of suitability for the Theory of Values (Borg et al., 2011), this study presents evidence that both work values and preferred organizational values can be used in studies of individual-organization values fit, since conceptual similarity between the different structures is demonstrated from the underlying motivations. This study thus contributes to the development of axiological fit indices by empirically showing the relationships predicted theoretically. Empirical arguments were developed for the commensurability between the organizational values and work values dimensions in using the comparison between the axiological dimensions of different levels of analysis. This model is based on conceptual similarity and not merely the use of identical items for the two levels without proper assessment of the motivational structure underlying the values of the individual and the organization.

In addition, the study has implications for professional practice in organizational socialization, vocational and career guidance, in pointing out the values of individuals which are more associated with certain organizational characteristics. In this way, those who seek to identify their values may have more clarity about the type of organization in which their inclusion could result in higher levels of well-being and organizational commitment, increasing their responsibility in the choices. Additionally, organizations can identify values of their employees in order to review their beliefs and practices to promote greater PO fit and develop effective socialization mechanisms. Finally, organizations that promote their practiced values can attract employees who share their vision, since people tend to prefer belief systems similar to their own.

Despite its contribution to the fit studies, this research does not address the effect of axiological fit on individual or organizational variables. Thus, further studies should be conducted to identify the impact of aligning individual and organizational values. In addition, this study was conducted with a sample consisting essentially of college students. For the present purpose, this does not present an obstacle as it sought to identify a preference for an ideal organization, and university students already have an image of the kind of organization where they would like to work. However future studies should test this model with workers with a lower education level and with a less idealized view of work. Furthermore, it is suggested to use techniques for reducing common method bias, such as hetero-evaluation or the use of time lapses between measurements. In addition, future studies may use multiple sources in the evaluation of organizational values, such as document reviews or shared perception, and test compatibility indexes once the validity of the measure for the theoretically predicted dimensions is firmly established. Thus, we expect to ensure a robust methodology for the PO fit area, together with the technique of checking the alignment with second order dimensions used in this study.

\section{References}

Borg, I., Groenen, P. J. F., Jehn, K. A., Bilsky, W., \& Schwartz, S. H. (2011). Embedding the organizational culture profile into Schwartz's universal value theory using multidimensional scaling with regional restrictions. Journal of Personnel Psychology, 10(1), 1-12. doi: 10.1027/1866-5888/a000028

Edwards, J. R. (2002). Alternatives to difference scores: Polynomial regression analysis and response surface methodology. In F. Drasgow \& N. W. Schmitt (Eds.), Advances in measurement and data analysis (pp. 350-400). San Francisco: Jossey-Bass.

Judge, T. A., \& Bretz, R. D. (1992). Effects of work values on job choice decisions. Journal of Applied Psycho$\log y$, 77, 261-271. doi: 10.1037/0021-9010.77.3.261

Kristof-Brown, A. L. Zimmerman, R. D., \& Johnson, E. C. (2005). Consequences of individuals' fit at work: A meta-analysis of person-job, person-organization, person-group, and person-supervisor fit. Personnel Psychology, 58, 281-342. doi: 10.1111/j.1744-6570.2005.00672.x

O’Reilly, C. A., Chatman, J. A., \& Caldwell, C. B. (1991). People and organizational culture: A profile comparison approach to assessing person-organization fit. Academy of Management Journal, 34, 487-516. Retrieved from http://faculty.haas.berkeley.edu/ chatman/papers/36_peopleorgculture.pdf

Porto, J. B., Ferreira, M. C., \& Fonseca, A. M. O. (2014). Organizational values: Structure and predictive power. In Porto, J. (Chair), Organizational culture: its dimensions and impact on individuals. Symposium at the 28th international Congress of Applied Psychology, Paris, France. 
Porto, J. B., \& Pilati, R. (2010). Escala revisada de valores relativos ao trabalho - EVT-R. Psicologia: Reflexão e Crítica, 23(1), 73-82. doi: 10.1590/ S0102-79722010000100010

Rokeach, M. (1981). Crenças, atitudes e valores. Rio de Janeiro: Interciência.

Ros, M., Schwartz, S. H., \& Surkiss, S. (1999). Basic individual values, work values, and the meaning of work. Applied Psychology: An International Review, 48, 49-71. doi: 10.1111/j.1464-0597.1999.tb00048.x

Sagiv, L., \& Schwartz, S. H. (2007). Cultural values in organisations: Insights for Europe. European Journal of International Management, 1, 176-190. doi: 10.1504/EJIM.2007.014692

Schneider, B, Goldstein, H. W., \& Smith, D. B. (1995). The ASA framework: An update. Personnel Psychology, 48, 747-773. doi: 10.1111/j.1744-6570.1995. tb01780.x

Schwartz, S. H. (1992). Universals in the content and structure of values: Theoretical advances and empirical tests in 20 countries. In M. P. Zanna (Ed.), Advances in Experimental Social Psychology (Vol. 25, pp. 1-65). San Diego: Academic. doi:10.1016/ S0065-2601(08)60281-6

Schwartz, S. H. (1994a). Are there universal aspects in the content and structure of values? Journal of Social
Issues, 50, 19-45. doi: 10.1111/j.1540-4560.1994. tb01196.x

Schwartz, S. H. (1994b). Beyond individualism/collectivism: New cultural dimensions of values. In U. Kim, H. C. Triandis, C. Kagitçibasi, S-C. Choi \& G. Yoon (Eds.). Individualism and collectivism. Theory, method, and applications (pp. 85-119). Thousand Oaks, CA: Sage.

Schwartz, S. H. (2003). Computing scores for the $10 \mathrm{bu}$ man values. European Social Survey data website. Retrieved from http://ess.nsd.uib.no/ess/doc/ ess1_human_values_scale.pdf

Sousa, J. M., \& Porto, J. B. (2012). Escala de Valores Organizacionais Preferidos. Comunicação breve de pesquisa apresentada no V Congresso Brasileiro de Psicologia Organizacional e do Trabalho da Sociedade Brasileira de Psicologia Organizacional e do Trabalho, Rio de Janeiro, Brasil.

Verquer, M., Beehr, T. A., \& Wagner, S. H. (2003). A meta-analysis of relations between person-organization fit and work attitudes. Journal of Vocational Behavior, 63(3), 473-489. doi: 10.1016/ S0001-8791(02)00036-2

Recebido em: 08/06/2014

Primeira reformulação em: 02/02/2015

Segunda reformulação em: 27/03/2015 Aprovado em: 22/04/2015 
Nota das autoras:

This research was supported by CNPq (Brazil) grant no. 303951/2010-9 to the second author.

We would like to thank Rafaela Moreira, who received an undergraduate scholarship from CNPq (PIBIC), for the support in data collection.

About the authors:

Juliana Moraes de Sousa has a master degree in Organizational Psychology (Universidade de Brasília- UnB). She works in project management at the public sector applying the concepts of values and cultural change to implement new paradigms in the sector. As graduation student in psychology, she worked in science projects related to environmental psychology, social psychology, consumer behavior and work well-being. E-mail: sousa.juliana@gmail.com

Juliana Barreiros Porto has a doctor degree in Psychology and is Professor at the Institute of Psychology, University of Brasília, Brasília, Brazil. She has expertise in Organizational Psychology and her research focuses primarily on organizational culture, work and personal values, person-organizational fit, well-being and proative behaviors at work. E-mail: porto.juliana@gmail.com

Corresponding author:

\section{UnB}

Juliana Barreiros Porto

Instituto de Psicologia - Departamento de Psicologia Social e do Trabalho

Universidade de Brasília, Campus Universitário Darcy Ribeiro, Instituto Central de Ciências Sul, Sala AT-013

Brasília, Brasil CEP: 70910-900 
